\title{
Pembuatan Alat Potong Tulang Sapi untuk Peningkatan Kinerja Panitia Qurban di Masjid Miftahul Jannah Kelurahaan Berua Kota Makassar
}

\begin{abstract}
Alang Sunding ${ }^{*}$, Nurul Afifah ${ }^{2}$
1,2 Politeknik Bosowa, Makassar, Indonesia *Corresponding Author: alang.sunding@gmail.com Info Artikel Diterima: 10/02/2022 Direvisi: 16/02/2022 Disetujui: 18/02/2022

Abstract. Every 10th of Dhul-Hijjah Muslims around the world celebrate eid al-Adha or known as the feast of Qurban. Almost every mosque, especially urban areas, organizes slaughter of qurban animals, as well as in the Miftahul Jannah Mosque. Based on information obtained from partners that almost every year the number of cows is more than goats for slaughter. In addition to meat, beef bones are also a part that is distributed by partners to those who are entitled to receive especially the shohibul qurban. In the resent years the bones that are distributed are large pieces so that it is a concern for partners because the recipient expects the size of the bone received to be ready to be cooked because not all residents who have equipment to cut bones. Based on this condition, it is necessary to make a bone cutting machine that can cut bones quickly with a ready-to-cook size of 10-15 cm. Utilization of bone cutting tools was carried out on eid al-Adha 10 Dhul-Hijjah $1442 \mathrm{H}$, coinciding on July 20,2021. The number of cows that are cut is 6 . The results of the implementation of the machine show that the equipment is functioning in accordance with the expectations of the partner. Based on the results of four mitra members showed that the machine can be operated easily, can cut quickly with a cut size of $10-15 \mathrm{~cm}$, and is safe to use. After cutting $6 \mathrm{cow}$ bones the machine still works well. Some input from partners is to expand the size of the table and improve the appearance of the machine so that it can be sold.
\end{abstract}

Keywords: Design, Cutting machine, Cow bone, Band saw

\begin{abstract}
Abstrak. Setiap tanggal 10 Dzulhijjah umat muslim seluruh dunia merayakan hari raya Idul Adha atau dikenal dengan hari raya qurban. Hampir setiap mesijd khususnya daerah perkotaan menyelenggarakan pemotongan hewan qurban, demikian juga di Mesjid Miftahul Jannah. Hewan qurban umumnya adalah sapi dan kambing. Berdasarkan informasi yang diperoleh dari mitra bahwa hampir setiap tahun jumlah sapi lebih banyak dari pada kambing untuk disembelih. Selain daging, tulang sapi juga menjadi bagian yang dibagikan oleh mitra kepada yang berhak menerima khususnya shohibul Qurban. Selama ini tulang yang dibagikan masih dalam bentuk potongan yang besar sehingga menjadi perhatian bagi mitra karena penerima mengharapkan ukuran tulang yang diterima siap dimasak karena tidak semua warga yang mempunyai peralatan untuk memotong tulang. Berdasarkan kondisi ini maka perlu dibuatkan mesin potong tulang yang dapat memotong tulang dengan cepat dengan ukuran yang siap masak yaitu $10-15 \mathrm{~cm}$. Pemanfaatan alat potong tulang dilaksnakan pada hari raya idul adha 10 Dzulhijjah $1442 \mathrm{H}$, bertepatan pada tanggal 20 Juli 2021. Jumlah yang sapi yang dipotong sejemlah 6 ekor. Hasil implementasi alat menunjukkan bahwa peralatan berfungsi sesuai dengan harapan mitra. Berdasarkan terstimoni dari empat orang anggota mintra menunjukkan bahwa mesin dapat dioperasikan dengan mudah, dapat memotong dengan cepat dengan ukuran hasil potongan $10-15 \mathrm{~cm}$, serta aman digunakan. Setelah memotong 6 ekor tulang sapi mesin masih berfungsi dengan baik. Beberapa masukan dari mitra adalah memperluas ukuran meja serta memperbaiki tampilan dari mesin agar bisa dijual.
\end{abstract}

Kata Kunci: Perancangan, Mesin potong, Tulang sapi, Band saw

How to Cite: Sunding, A., \& Afifah, N. (2022). Pembuatan Alat Potong Tulang Sapi untuk Peningkatan Kinerja Panitia Qurban di Masjid Miftahul Jannah Kelurahaan Berua Kota Makassar. Prima Abdika: Jurnal Pengabdian Masyarakat, 2(1), 69-74. https://doi.org/10.37478/abdika.v2i1.1699

Copyright (c) 2022 Alang Sunding, Nurul Afifah. This work is licensed under a Creative Commons Attribution-ShareAlike 4.0 International License.

\section{Pendahuluan}

Setiap tanggal 10 Dzulhijjah umat muslim merayakan hari raya Idul Adha atau yang dikenal dengan hari raya Qurban. Hampir setiap masjid khususnya yang berada dikota mulai dari Masjid Raya Sampai Masjid yang berada dilingkungan Komplek Perumahan melaksanakan pemotongan hewan qurban. Menyembelih hewan qurban pada hari raya Idul Adha merupakan salah satu ibadah yang mulia dan penting dalam Islam. Shohibul qurban atau 
muslim yang berqurban biasanya menyerahkan ternaknya ke masjid untuk dikelola oleh panitia penyembelihan hewan qurban, karena tidak setiap muslim yang berqurban mampu melakukan penyembelihan hewan qurban dan mendistribusikan daging qurban sendiri (Awaludin, 2017).

Sapi dan kambing merupakan hewan yang umum dijadikan pilihan untuk disembelih saat hari raya qurban. Sapi menjadi pilihan utama shohibul qurban, berdasarkan informasi dari mitra bahwa setiap tahun jumlah sapi lebih banyak dari pada kambing yang disembelih.

Sapi merupakan hewan yang menjadi komoditas pangan utama khususnya di Indonesia. Hampir segala bagian dari sapi habis tak bersisa untuk dijadikan berbagai macam hal. Salah satunya adalah tulang sapi. Hampir setiap makanan menggunakan bahan tulang ini entah dijadikan sebagai kaldu, atau dijadikan sebagai makanan itu sendiri yaitu untuk diambil sumsumnya (Adrianto et al., 2019).

Pelaksana atau panitia penyelenggara kegiatan pemotongan hewan qurban umumya adalah warga setempat yang merupakan jamaah masjid Miftahul Jannah, baik yang terdaftar sebagai orang yang menyerahkan hewan qurban (shohibul qurban) maupun yang tidak berqurban. Panitia pemotongan hewan qurban di Mesjid Miftahul Jannah yang selanjutkan akan disebut sebagai mitra umumnya terbagi kedalam beberapa bagian antara lain : seperti bagian pemotongan dan pengulitan, bagian pemotong daging dan tulang, serta bagian distribusi.

Bagian pemotongan dan pengulitan selama ini dilakukan dengan cara membayar orang yang ahli dalam merebahkan dan memotong sapi sesuai syariat islam termasuk proses pengulitan, pembersihan isi perut, serta membagi sapi yang sudah dikuliti menjadi beberapa potongan besar yang terdiri atas bagian kaki sampai dengan paha bagian depan dan belakang, bagian badan berupa tulang rusuk dan punggung serta bagian kepala.

Bagian pemotongan daging dan tulang serta bagian distribusi dilakukan oleh mitra. Proses pemisahaan daging dari tulang dapat dilakukan dengan mudah karena tidak membutuhkan peralat khusus cukup dengan pisau yang tajam. Kendala yang dihadapi panitia adalah saat memotong tulang terutama bagian tulang kaki dan punggung yang sangat keras sehingga membutuhkan peralatan khusus seperti kapak serta parang yang besar dan kuat. Memotong tulang dengan kapak atau parang kurang aman dan tidak ergonomik, sehingga terkadang mencelakakan pekerja dan juga berpotensi menimbulkan sakit pada lengan jika dilakukan tidak hati-hati (Zulfikri, 2021).

Berdasarkan kondisi ini maka diperlukan peralatan khusus untuk membantu mitra memotong tulang dengan cepat dengan menggunakan motor penggerak atau mesin. Hampir semua pekerjaan manusia dapat dikerjakan dengan cepat dan mudah. Hal ini dikarenakan adanya mesin-mesin yang sengaja diciptakan untuk mempermudah pekerjaan manusia. Selain mempermudah pekerjaan manusia, penggunaan mesin sangat membantu dalam meningkatkan produktifitas dengan waktu yang relatif lebih cepat (Ardi et al., 2019).

Beberapa metode yang dapat dilihat di chanel youtube yang telah diperagakan dengan melakukan modifikasi peralatan menggunakan gerinda 
tangan, menggunakan cyrcle saw, menggunakan system penekanan (press) dan menggunakan band saw.

Tujuan pembuatan alat ini adalah untuk membantu mempermudah mitra memotong tulang sapi dengan menggunakan mesin. Menghasilkan potongan yang siap dimasak ukuran $10-15 \mathrm{~cm}$.

\section{Metode Pelaksanaan}

Metode pelaksanaan pengabdian ini mengacu pada 8 konsep pengembangan produk yaitu : 1. Penciptaan ide produk, 2. Penyaringan atau pemilihan ide produk, 3. Pengembangan dan pengujian konsep, 4. Pengembangan strategi pemasaran, 5. Analisa bisnis, 6. Pengembangan produk, 7. Uji pemasaran (skala kecil), 8. Komersialisasi (Firmansyah \& Roosmawarni, 2019). Namun dalam proses pembuatan alat, pelaksana hanya melaksanaakan tiga konsep pengembangan karena dalam pelaksaanannya hanya akan dilihat fungsi alat apakah dapat meningkatkan kinerja mitra. Tiga konsep pengembangan adalah sebagia berikut :

1. Penciptaan ide produk

Penciptaan ide produk dimulai dengan konsep ATM (Amati, Tiru dan Modifikasi). Pengamatan dilakukan dengan melihat peralatan yang berhubungan dengan pemotongan tulang yang dikembangkan masyarakat di channel Youtube.

Ada 4 ide yang diamati sebagai berikut :

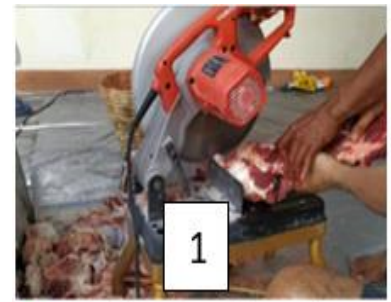

Memilih Gerinda untuk Potong Tulang Sapi

Thiang Hobi-28K views 1 year ago

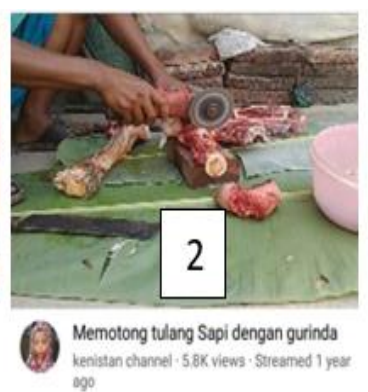

keno
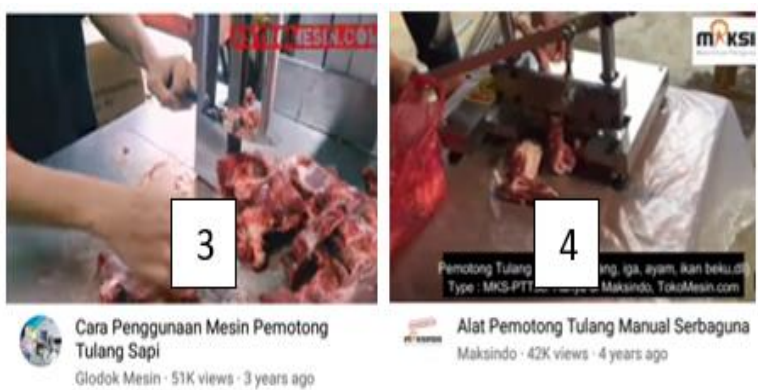

Alat Pemotong Tulang Manual Serbaguna thaksindo - 42 K views 44 yeart ags

Gambar 1. Pemilihan konsep prinsip kerja alat yang akan dibuat

Gambar 1.1 menggunakan mesin cut off yang biasa digunakan untuk memotong besi, aluminiun dan kayu. Prinsip kerja tulang diletakkan pada landasan kemudian alat potong diturunkan dengan cara memegang handle mesin. Gambar 1.2 menggunakan mesin gerinda tangan (hand grinding) untuk memotong tulang dengan cara penggunaan seperti umumnya. Mata potong diganti dengan menggunakan mata gerinda keramik. Gambar 1.3 Menggunakan mesih band atau banyak dikenal dengan isilah gergaji pita karena bentuk mata potong seperti pita yang melingkar. Proses pemotongan dilakukan dengan meletakkan tulang diatas meja kemudian dengan menggunakan pendorong khusus hingga tulang melintasi mata potong. Gambar 1.4 Menggunakan sistem tekan (press), prinsip kerja benda diletakkan diantara landasan dan alat potong. Kemudian alat potong diturukan menggunakan alat penekan hingga memotong tulang. 


\section{Penyaringan atau pemilihan ide}

Penyaringan ide dari konsep produk dilakukan dengan beberapa pertimbangan antara lain : Tingkat keamanan penggunaan alat, kecepatan proses pemotongan, sumber listrik dan harga.

3. Pengembangan dan pengujian konsep

Pengembangan dan pengujian konsep dilakukan setelah pemilihan ide kemudian dilakukan modifikasi baik untuk mempermudah pembuatan maupun untuk menekan biaya pembuatan.

\section{Hasil dan Pembahasan}

Penyaringan atau pemilihan ide dilakukan dengan menggunakan matrik penilaian berdasarkan kecepatan proses pemotongan tingkat keamanan penggunaan alat, Kualitas hasil pemotongan dan harga (Herlina \& Rizani, 2013). Penilaian berdasarkan angka 1 - 4. Angka 1 berarti penilaian kurang, angka 2 berarti cukup, angka 3 berarti baik dan angka 4 barati baik sekali.

Tabel 1. Pemilihan ide untuk pemotong tulang

\begin{tabular}{lcccc}
\hline Penilaian dan objek yang dinilai & $\begin{array}{c}\mathrm{G} 1.2 \\
\text { Cut off }\end{array}$ & $\begin{array}{c}\mathrm{G} 1.2 \\
\text { Hand } \\
\text { grinding }\end{array}$ & $\begin{array}{c}\mathrm{G} 1.3 \\
\text { Bandsaw }\end{array}$ & $\begin{array}{c}\text { G1.4 } \\
\text { Press }\end{array}$ \\
\hline kecepatan proses pemotongan & 3 & 1 & 4 & 2 \\
Tingkat keamanan penggunaan & 2 & 1 & 3 & 4 \\
Kualitas hasil pemotongan & 3 & 2 & 4 & 1 \\
Harga lebih murah & 3 & 4 & 2 & 1 \\
\hline \multicolumn{1}{c}{ Total Nilai } & 11 & 8 & 13 & 8 \\
\hline
\end{tabular}

Berdasarkan tabel 1, diperoleh matrik penilaian tertinggi adalah dengan prinsip pemotongan band saw. Berdasarkan harga peralatan mesin band saw lebih mahal dari mesin cut off namun dengan cara membuat sendiri dan melakukan modifikasi harga mesin bisa sebanding dengan harga mesih cut off sehingg disimpulan bahwa mesin pemotong tulang yang akan digunakan dengan prinsip band saw .

Mesin band saw atau gergaji pita adalah mesin perkayuan yang mempunyai mata gergaji bentuk pita. Mesin gergaji pita banyak digunakan di industri untuk memotong lurus, lengkung, juga untuk memotong bentukbentuk yang tidak beraturan (Silviana \& Ismail, 2017). Mesin ini sangat cocok untuk pemotongan tulang yang bentuknya tidak beraturan.

Untuk membuat mesin potong tulang dengan prinsip kerja band saw membutuhkan alat dan bahan berupa : Motor listrik $1 \mathrm{hp}, 2$ buah pulley 4 inch, mata gergaji pita, dua buah roda, 2 buah bearing duduk ukuran 1 inch, bahan rangka dari besi hollow ukuran $4 \times 6 \mathrm{~cm}$ serta multiplek $15 \mathrm{~mm}$.

Penggunaan alat potong tulang dilaksnakan pada hari raya idul adha 10 Dzulhijjah $1442 \mathrm{H}$, bertepatan pada tanggal 20 Juli tahun 2021. Jumlah yang sapi yang dipotong sejemlah 6 ekor. 

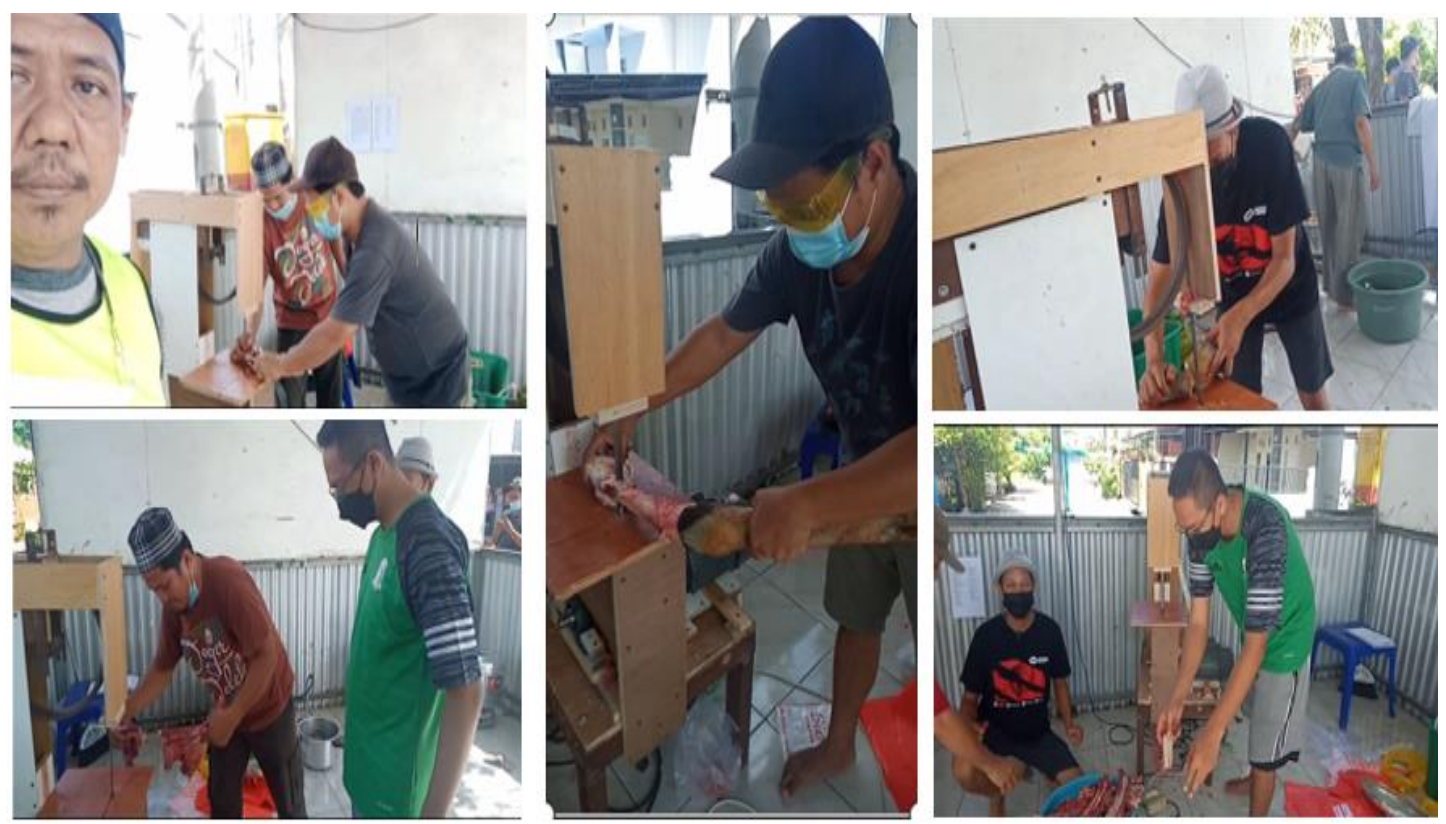

Gambar 2. Implementasi alat pemotong tulang oleh anggota mitra

Keterangan fungsi alat berdasarkan terstimoni anggota mitra yang menggunakan alat.

Tabel 2. Testimoni anggota mitra yang mengoperasikan alat

\begin{tabular}{l|l}
\hline \multicolumn{1}{c|}{ Nama } & \multicolumn{1}{c}{ Testimoni } \\
\hline Abdullah & - Peralatan aman dan mudah digunakan \\
& - Pemotongan cepat \\
& - Kualitas pemotongan baik \\
& - Meja perlu diperbesar \\
& - Perlu karet dibagian kaki untuk mengurangi \\
& getaran \\
\hline Gunawan & - Peralatan aman dan mudah digunakan \\
Samsuddin & - Pemotongan cepat \\
& - Kualitas pemotongan baik \\
\hline Agung Putra & - Peralatan aman dan mudah digunakan \\
& - Pemotongan cepat \\
& - Kualitas pemotongan baik \\
& - Tampilan alat perlu diperbaiki agar dapat \\
& dikomersilkan \\
\hline Sapril & - Peralatan mudah dan aman digunakan \\
& - Kualitas pemotongan baik \\
& - Sangat membantu \\
\hline
\end{tabular}

\section{Simpulan dan Tindak Lanjut}

Berdasarkan informasi dari anggota mitra yang menggunakan alat menyatakan bahwa alat yang telah dibuat sangat membantu mitra untuk menyelesaikan pekerjaan. Aman dan mudah dalam pengoperasian, tidak perlu waktu lama untuk mempelajari prinsip kerjanya. Saran untuk pengembangan peralatan adalah ukuran meja diperbesar, tambahan pendorong atau penarik untuk membantu proses pemotongan serta karet 
kaki untuk mengurangi getaran. Tindak lanjut kegiatan adalah perbaikan beberapa fungsi alat berdasarkan testimoni yang menggunakan agar kinerja alat lebih baik dan bisa digunakan dalam waktu yang lama. Perbaikan tampilan alat agar dapat dikomersilkan.

\section{Daftar Pustaka}

Adrianto, J., Setiawan, A. P., \& Tanaya, F. (2019). Eksperimen Dengan Media Tulang Sapi Sebagai Media Alternatif Produk Interior. Jurnal Intra, 7(2).

Ardi, A., Rijanto, A., \& Kurniawan, S. E. (2019). Rancang Bangun Mesin Pemotong Balok Kayu Serbaguna Dengan Sistem Kontrol. Majamecha, 1(2), 77-87.

Awaludin, A. (2017). PROGRAM PENGABDIAN KEPADA MASYARAKAT TEKNIK HANDLING DAN PENYEMBELIHAN HEWAN QURBAN. Jurnal Pengabdian Masyarakat Peternakan, 2(2). https://doi.org/10.35726/jpmp.v2i2.209

Firmansyah, A., \& Roosmawarni, A. (2019). Kewirausahaan (Dasar dan Konsep. In Buku (Issue September).

Herlina, F., \& Rizani, A. (2013). Rancang Bangun Alat Pemotong Bahan Kerupuk Ubi Kayu. INFO TEKNIK, 14(1).

Silviana, S. \& Ismail, N. R. (2017). PENINGKATAN PRODUKTIFITAS PROSES PRODUKSI PENGRAJIN KUSEN DAN PINTU BERBASIS MESIN BAND SAW. SENASPRO, 349-355.

Zulfikri, Z. (2021). Modifikasi Hand Press Standar Menjadi alat potong tulang Kaki Sapi. 